- Informs patients that smoking increases alveolar bone loss and tooth loss.

- The effect of tobacco smoking increases with age - the duration of the habit is an important factor.

- Smokers have more deep pockets - this will increase treatment need and complexity.

\title{
A retrospective study of periodontal disease severity in smokers and non-smokers
}

\author{
M. Razali, ${ }^{1}$ R. M. Palmer, ${ }^{2}$ P. Coward ${ }^{3}$ and R. F. Wilson ${ }^{4}$
}

\begin{abstract}
Background Smoking has been associated with increased risk of periodontitis. The aim of the present study was to compare the periodontal disease severity of adult heavy smokers and never-smokers referred for assessment and treatment of chronic periodontitis. Methods A random sample of patients with at least 20 teeth, stratified for smoking and age (5-year blocks, 35 to 55 years), was selected from an original referral population of 1,221 subjects with chronic adult periodontitis. Adequate records for 59 never-smokers and 44 subjects who smoked at least 20 cigarettes per day were retrieved. The percentage of alveolar bone support was measured from dental panoramic radiographs with a Schei ruler at $x 3$ magnification with the examiner unaware of the smoking status. Probing depths at six sites per tooth were obtained from the initial consultation.

Results There was no significant difference in age between groups. Smokers had fewer teeth $(p<0.001)$, fewer shallow pockets $(p<0.001)$ and more deep probing depths $(p<0.001)$. The differences were greater in subjects 45 years of age and over. In this age group, smokers had approximately $13 \%$ more bone loss, $15 \%$ more pockets in the 4-6 mm category and $7 \%$ more pockets in the $\geq 7 \mathrm{~mm}$ category than the neversmokers.

Conclusions This study confirmed that smokers had evidence of more severe periodontal disease than never-smokers. The differences increased with age confirming an exposure-related response.
\end{abstract}

\section{INTRODUCTION}

An overwhelming body of epidemiological evidence supports the conclusion that cigarette smoking is a major risk factor in cardiovascular, peripheral vascular and cerebral vascular diseases, chronic obstructive pulmonary diseases and cancer at many sites, including the lung, larynx, oral cavity, oesophagus and bladder. ${ }^{1}$ Cigarette smoking is now regarded as a major risk factor for periodontitis. ${ }^{2-8}$

\footnotetext{
${ }^{1}$ Lecturer and specialist in Periodontology, Dental Faculty, Universiti Kebangsaan Malaysia, Kuala Lumpur, ${ }^{2 *}$ Professor of Implant Dentistry and Periodontology, ${ }^{3}$ Laboratory Scientific Officer, ${ }^{4}$ Senior Lecturer, Department of Periodontology, Kings College London, GKT Dental School, London

${ }^{*}$ Correspondence to: Professor Richard M. Palmer, Department of Periodontology, Floor 21, Guy's Hospital Tower, London SE1 9RT

Email richard.m.palmer@kcl.ac.uk
}

\section{Refereed paper}

Received 02.02.04; Accepted 07.04.04

doi: $10.1038 /$ sj.bdj.4812253

๑ British Dental Journal 2005; 198: 495-498
A direct correlation between tobacco use and increased attachment loss and pocket depth and reduced bone crest height was reported as early as $1959 .{ }^{9}$ Subsequent studies such as those by Feldman et al. ${ }^{10}$ and Ismail et al. ${ }^{11}$ showed that cigarette smokers showed significantly greater mean pocket depth scores and greater alveolar bone loss than non-smokers. Bergström and Elíasson ${ }^{12}$ in their study of 242 subjects (76 smokers) clearly demonstrated the relatively greater occurrence of pockets in smokers matched for age and oral hygiene. Haber and Kent ${ }^{13}$ compared the prevalence of cigarette smoking among patients in a periodontal practice (cases) with that of patients from referring general practitioner (controls). They concluded that both current and former smokers are at increased risk for periodontitis, and that cigarette smoking is a major environmental risk factor for periodontitis.

A more recent study by Bergström et al, ${ }^{14}$ showed that smokers had a significantly greater frequency of diseased sites and a significantly greater reduction of periodontal bone height than nonsmokers. The periodontal condition of former smokers was between that of current smokers and non-smokers. Heavy exposure to smoking was consistently associated with more severe disease than light exposure, suggesting that the relationship is dose-dependent. ${ }^{14,15}$ In another recent investigation by Haffajee and Socransky, ${ }^{16}$ smokers had evidence of more severe periodontal disease than past or never-smokers, indicated by higher mean loss of attachment.

The purpose of the present study was to establish retrospectively whether the disease severity differs between smokers and nonsmokers, in a well defined group of middle-aged adults diagnosed with chronic periodontitis who were referred to the Department of Periodontology, Guy's and St. Thomas' Hospital Trust, London.

\section{MATERIAL AND METHODS}

Subject sampling

The total number of new patient referrals seen for initial consultation and diagnosed with chronic periodontitis between May 2001 and May 2002 was 1,221 (including mild, moderate and severe disease). This included 403 smokers and 579 never-smokers aged between 35 and 55 years. From this, 5 pregnant women and 21 diabetic individuals were excluded. After exclusion of subjects with fewer than 20 teeth (excluding third molars) and smokers who smoked less than 20 cigarettes per day, this left 94 smokers and 336 never-smokers from whom the random sample was selected. A sample of 18 current heavy smokers and 18 


\begin{tabular}{|c|c|c|c|c|c|}
\hline \multirow[t]{2}{*}{ Age (years) } & \multicolumn{4}{|c|}{ Smoking status } & \\
\hline & \multicolumn{2}{|c|}{$\begin{array}{c}\text { Smokers } \\
\mathrm{n}=44\end{array}$} & \multicolumn{2}{|c|}{$\begin{array}{c}\text { Never- smokers } \\
n=59\end{array}$} & \\
\hline $\begin{array}{l}<45 \\
>45 \\
\text { Total }\end{array}$ & $\begin{array}{c}\text { Male } \\
4 \\
14 \\
18\end{array}$ & $\begin{array}{c}\text { Female } \\
18 \\
8 \\
26\end{array}$ & $\begin{array}{c}\text { Male } \\
5 \\
7 \\
12\end{array}$ & $\begin{array}{c}\text { Female } \\
24 \\
23 \\
47\end{array}$ & $\begin{array}{c}\text { Total } \\
51 \\
52 \\
103\end{array}$ \\
\hline
\end{tabular}

never-smokers were randomly selected from each of four age strata between 35-55. A total of 103 patients had adequate clinical notes and radiographs for inclusion in the study.

The patients had dental panoramic tomographs (DPTs) and probing pocket depth charts obtained during their initial consultation. Probing depth charts (six sites per tooth) were completed by various specialist periodontists and senior undergraduate dental students under their supervision. Medical and smoking history was collected by means of self-reporting following standardised medical questionnaires at the same appointment.

No attempt was made to validate the smoking history by measures such as serum or salivary cotinine levels.

\section{Radiographic measurement of alveolar bone support}

The dental panoramic radiographs and photocopied probing depth charts were coded and read by a single examiner (MR) who was kept blind as to the age, gender and smoking status.

The alveolar bone crest in relation to root length was measured according to the method described by Schei et al. ${ }^{9}$ which is commonly used in studies evaluating bone support. ${ }^{17-19}$ The ruler was modified in such a way that the total 40 lines corresponded to $100 \%$ of total bone support, each portion corresponding to $2.5 \%$ of bone support. In cases where the bone level lay between the 2 lines, the score was rounded down. A clear plastic-tracing sheet was placed over the DPT and the image was projected onto a viewing screen (Rinn Viewer and Magnifier, USA) at X3 magnification. The outlines of apices, the cemento-enamel junctions (CEJs) on mesial and distal surfaces and the proximal alveolar bone crest were traced for all measurable teeth. All the identifiable landmarks were marked with a $0.5 \mathrm{~mm}$ felt-tip pencil. The crest of the alveolar bone was defined as the most coronal level at which the periodontal ligament retained its normal width. Where there was an angular bone defect evident radiographically, the bone level was defined as the most apical point of the defect ${ }^{19}$ and used for measurement. A site was scored as unreadable if at least one of the reference points that needed to be measured could not be identified.

Repeated, non-consecutive radiographic evaluations were used for determination of intra-examiner reliability. Ten repeat radiographs chosen at random were assigned a separate number so that the examiner was blind to the repeat radiographs.

\section{Statistical analysis}

The data obtained was entered into statistical package (STATA 6, Stata Co. Tx, USA) for statistical analyses. The patient constituted the statistical unit. The subjects were further divided into two groups: under 45 years of age and 45 years and above.

The clinical data were expressed as means and standard deviation for both percentage radiographic bone support and probing depth. Probing depth was also analysed as percentage of sites 1-3 $\mathrm{mm}, 4-6 \mathrm{~mm}$ and $\geq 7 \mathrm{~mm}$. The statistical significance of differences between smoking and never-smoking subjects was calculated according to the two-sample $t$ test with equal variances. A p value of $\leq 0.05$ was accepted as statistically significant. The intra-examiner reproducibility was estimated by intra-class correlation and the percentage of agreement on a site-based assessment.

\section{RESULTS}

The final sample of 44 smokers and 59 never-smokers matched for age and who had complete periodontal probing depth charts and dental panoramic tomograms is presented in Table 1 . The mean age of smokers and never-smokers were $45.0 \pm 5.7$ and $45.4 \pm 5.8$ years respectively. There were no statistically significant differences in age between subject groups, but the proportion of males and females was different between smokers and never-smokers in the older age group.

\section{Radiographic bone support}

Smokers had statistically significantly less mean percentage of radiographic bone support than never-smokers (smokers 68\% [95\% confidence intervals (CI): 64-71], never-smokers 78\% [95\% CI 75-80], $\mathrm{p}<0.001)$.

The results from the analysis of subjects less than 45 years of age and 45 years and over are presented in Tables 2 and 3 respectively. The difference in bone levels between smokers and neversmokers was larger in the older age group ( $7-9 \%$ difference for $<45$ year age group and $12-13 \%$ for $>45$ year age group).

\begin{tabular}{|c|c|c|c|}
\hline & $\begin{array}{l}\text { Never-smokers } \\
\quad(n=29)\end{array}$ & $\begin{array}{l}\text { Smokers } \\
(n=22)\end{array}$ & \\
\hline Mean age & $40.4 \pm 2.6$ & $40.1 \pm 2.8$ & $p=0.621$ \\
\hline Gender & $\begin{array}{c}\text { Male }=5 \\
\text { Female }=24\end{array}$ & $\begin{array}{c}\text { Male }=4 \\
\text { Female }=18\end{array}$ & $p=0.930$ \\
\hline \multicolumn{4}{|c|}{$\begin{array}{l}\text { Mean } \% \text { of bone } \\
\text { support [ } 95 \% \mathrm{Cl}]\end{array}$} \\
\hline $\begin{array}{l}\text { Mesial } \\
\text { Distal } \\
\text { Total }\end{array}$ & $\begin{array}{l}80[76-83] \\
78[74-82] \\
79[75-82]\end{array}$ & $\begin{array}{l}71[68-74] \\
71[68-73] \\
71[68-73]\end{array}$ & $\begin{array}{l}p<0.001 \\
p=0.004 \\
p=0.001\end{array}$ \\
\hline
\end{tabular}

\section{Probing pocket depths}

Smokers had significantly fewer teeth than never-smokers (Table 4). Smokers had higher mean probing depths, more pockets with sites of 4-6 $\mathrm{mm}$ and a lesser percentage of shallow pockets. However, the difference in percentage of deeper pockets of $\geq 7 \mathrm{~mm}$ was not significant.

The probing depths subcategorised into the two age groups are presented in Table 5 and Table 6 . In the younger group, smokers had slightly fewer teeth $(\mathrm{p}<0.002)$, but there was no difference in mean probing depth between smokers and never-smokers. When comparison was made in term of percentages of sites, smokers exhibited fewer shallow probing depths and more moderate (4-6 mm) probing depths $(\mathrm{p}=0.036)$.

\begin{tabular}{|c|c|c|c|}
\hline & $\begin{array}{l}\text { Never-smokers } \\
(n-30)\end{array}$ & $\begin{array}{c}\text { Smokers } \\
(n=22)\end{array}$ & \\
\hline Mean age & $50.2 \pm 3.2$ & $50.0 \pm 2.7$ & $p=0.783$ \\
\hline Gender & $\begin{array}{c}\text { Male }=7 \\
\text { Female }=23\end{array}$ & $\begin{array}{l}\text { Male }=14 \\
\text { Female }=8\end{array}$ & $p=0.005$ \\
\hline \multicolumn{4}{|c|}{$\begin{array}{l}\text { Mean } \% \text { of bone } \\
\text { support }[95 \% \mathrm{Cl}]\end{array}$} \\
\hline Mesial & $78[74-81]$ & $65[59-70]$ & $p<0.001$ \\
\hline Distal & 76 [72 - 79] & $64[59-69]$ & $p<0.001$ \\
\hline Total & $77[73-80]$ & $64[59-70]$ & $p<0.001$ \\
\hline
\end{tabular}


In the older group (Table 6), smokers had significantly fewer teeth $(p=0.033)$, higher mean probing depths $(p=0.006)$, and higher percentages of deep pockets $(4-6 \mathrm{~mm}[\mathrm{p}=0.001]$ and $\geq 7 \mathrm{~mm}$ $[p=0.09])$.

\section{Intra-examiner reproducibility}

Assessment and repeated measurement of 10 panoramic radiographs showed that 56\% of surfaces scored the same and $88 \%$ were scored within 5\% differences. The intra-class correlation coefficient $\left(\mathrm{r}_{\mathrm{i}}\right)$ was 0.94 .

\section{DISCUSSION}

The present study confirms previous reports that subjects who smoke cigarettes have a greater risk of more severe alveolar bone

\begin{tabular}{lccc}
\multicolumn{4}{l}{ Table 4 Mean percentage of probing depth of all subjects } \\
\hline & $\begin{array}{c}\text { Never-smokers } \\
(n=59)\end{array}$ & $\begin{array}{c}\text { Smoker } \\
(n=44)\end{array}$ & p value \\
\hline $\begin{array}{l}\text { Mean number } \\
\text { of teeth [95\% Cl] }\end{array}$ & $27.9[27.1-28.6]$ & $25.7[24.9-26.6]$ & $<0.001$ \\
\hline Mean probing depth & & & \\
$(\mathrm{mm})[95 \% \mathrm{Cl}]$ & $3.37(3.16-3.59)$ & $3.91(3.64-4.18)$ & 0.002 \\
\hline$\%$ Probing depth & & \\
{$[95 \% \mathrm{Cl}]$} & $66.2(61.0-71.3)$ & $51.1(43.8-58.3)$ & $<0.001$ \\
\hline $1-3(\mathrm{~mm})$ & $25.6(21.9-29.4)$ & $38.7(33.0-44.5)$ & $<0.001$ \\
$4-6(\mathrm{~mm})$ & $8.6(5.8-11.4)$ & $12.2(8.5-15.9)$ & 0.116 \\
$\geq 7(\mathrm{~mm})$ & &
\end{tabular}

loss and deeper pockets. ${ }^{14,20-22}$ The subject groups evaluated in previous studies have been very variable in terms of periodontal susceptibility and exposure to smoking. They have sometimes suffered from lack of suitable control subjects and adequate blinding of the examiners. Susceptibility to periodontitis is complex and includes genetic, host, bacterial and environmental factors. The subjects in the present study were all identified as susceptible individuals in that they were diagnosed with chronic periodontitis in primary care and referred to a specialist department. In each case, this diagnosis was confirmed by the consultant in that department. The relatively young age range of the subjects was chosen to reduce the problem of more extensive tooth loss in older individuals. The smokers and never-smokers were identified on the basis of self-report and no validation was made using $\mathrm{CO}$ monitors or cotinine assays. ${ }^{23}$ The smoking subjects were selected on the basis of reported smoking of at least 20 cigarettes per day. This is a high consumption and it is likely that this was a true reflection of their smoking habit. For the most part, smokers tend to under-report their level of smoking rather than exaggerate it. It is highly unlikely that this group contained non-smokers ie subjects reporting that they smoke when in fact they did not. The converse is much more likely where there is a real possibility that a few subjects in the neversmoking group were 'deceivers' and in fact smoked. This problem would however reduce the likelihood of demonstrating a difference between the two groups. Most smoking individuals commence the habit in their teenage years. ${ }^{1}$ This would indicate that the smokers in the present study smoked for between 20 and 40 years. At the two extremes, the lifetime exposure of these subjects could represent double the exposure. One of the most interesting findings of the present study was the comparison of the bone levels between the age groups and with other studies. Bergström and co-workers ${ }^{14}$ evaluated 257 musicians aged range 20 - 69 years, including 50 smokers and 133 non-smokers. They were chosen as a relatively homogenous group of professional motivated individuals with access to good dental care. They were not selected on the basis of periodontal susceptibility.

\begin{tabular}{lccc}
\multicolumn{4}{l}{ Table 5 Mean probing depth of subjects less than $\mathbf{4 5}$ years of age } \\
\hline & $\begin{array}{c}\text { Never-smokers } \\
(n=29)\end{array}$ & $\begin{array}{c}\text { Smoker } \\
(n=22)\end{array}$ & p value \\
\hline $\begin{array}{l}\text { Mean number of } \\
\text { teeth }[95 \% \mathrm{Cl}]\end{array}$ & $28.5[27.4-29.5]$ & $25.9[24.7-27.1]$ & 0.002 \\
\hline $\begin{array}{l}\text { Mean probing } \\
\text { depth }(\mathrm{mm})\end{array}$ & & & \\
{$\left[\begin{array}{l}95 \% \mathrm{Cl}] \\
\text { \% Probing depth }\end{array}\right.$} & $3.42(3.08-3.75)$ & $3.68(3.37-3.99)$ & 0.251 \\
\hline $95 \% \mathrm{Cl}]$ & & & \\
\hline $1-3(\mathrm{~mm})$ & $65.0(57.4-72.6)$ & $56.0(46.0-66.0)$ & 0.139 \\
$4-6(\mathrm{~mm})$ & $26.8(21.5-32.0)$ & $37.1(28.1-46.1)$ & 0.036 \\
$\geq 7(\mathrm{~mm})$ & $7.9(4.9-10.9)$ & $8.3(5.5-11.1)$ & 0.836 \\
\hline
\end{tabular}

Nevertheless, this group showed a difference in bone levels of about 5\% between smokers and non-smokers in the age group 40 - 69 years, but no difference in subjects less than 40 years of age. The average cigarette consumption was 13.3 cigarettes per day for an average of 20.4 years, somewhat lower than the present study. The difference in bone levels between smokers and never-smokers in the present study is greater than that previously reported and was highly significant in both age groups. When comparing bone level in the two age groups, the difference in the never-smokers was minimal. However, the older age group of smokers had approximately 7\% more bone loss compared to the younger smoking group. It is pertinent to note that the percentage bone level in the older age group of never-smokers (77\% [95\%CI 73-80]) was more favourable than the bone level in the younger group of smokers (71\% [95\%CI 68-73]). As the difference in mean age between the two groups was about 10 years, this could be interpreted that the smoking habit had contributed at least the equivalent of an additional '10 years' worth' of periodontal destruction. The greater differences observed in the present study are probably due to the high exposure to smoking of at least 20 cigarettes per day, for at least 20 years (assuming most smokers start in their early to mid teens).

The smokers also had greater mean probing depths and more deep pockets. Smokers may have less overt inflammation, which tends to reduce the estimate of probing depth, ${ }^{24-26}$ thereby decreasing the chance of showing a difference. Probing depth is not a direct measure of periodontal destruction and periodontal attachment loss is to be preferred. ${ }^{16}$ However, studies show that

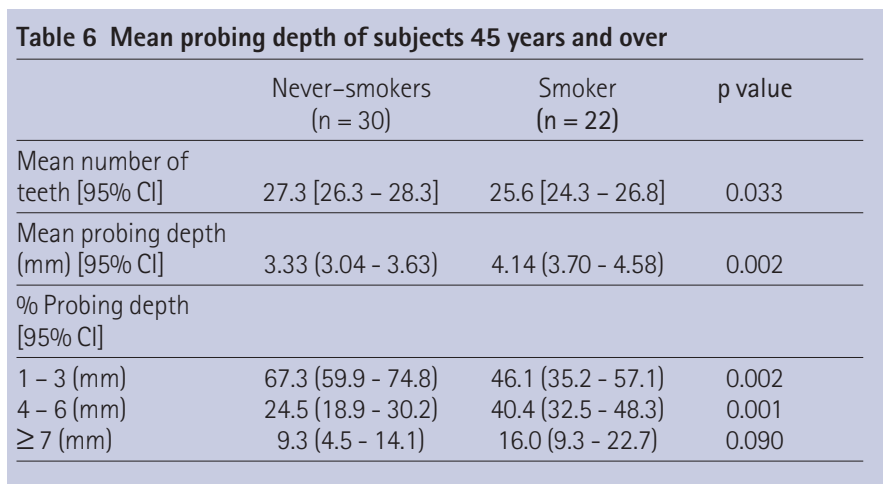

smokers tend to have more gingival recession, which would contribute to the estimate of attachment loss. ${ }^{26}$ Therefore, observed differences in probing depths between smokers and never-smokers will tend to favour an underestimate of disease in smokers. The present probing depth data indicates that the disease is more severe and more widespread in smokers. The differences in disease severity estimated by probing depth were also greater than those described in previous reports, paralleling the findings of bone support. For example, in the study of Haber and Kent ${ }^{13}$ on patients 
referred to a private periodontal practice, they recorded a mean proportion of sites probing $\geq 4 \mathrm{~mm}$ to be $35 \%$ in smokers compared to $21 \%$ in non-smoker control patients from a general practice. These figures were similar to those reported by Bergström² in a study of patients referred to a specialist periodontal clinic [Propor-

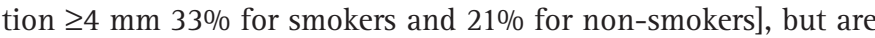
much lower than the 49\% in smokers and 34\% in never-smokers in the present study. These findings confirm that the subjects in the present study referred to a specialist department were very susceptible to periodontitis and that the smoking group were especially at risk due to their heavy smoking habit.

\section{CONCLUSIONS}

In agreement with other studies, smoking increases the risk of periodontal disease. Smokers had evidence of more severe periodontal disease manifested by more bone loss and deeper probing depths compared to never-smokers. The differences were present in the younger age group and increased with age confirming a dose/exposure response.

1. Department of Health. Smoking kills. A White Paper on tobacco. London: The Stationery Office, 1998.

2. Bergström J. Cigarette smoking as a risk factor in periodontal disease. Commun Dent Oral Epidemiol 1989; 17: 245-247

3. Bergström J. Tobacco use as a risk factor. J Periodonto/ 1994; 65: 545-550.

4. Palmer R M, Tobacco smoking and oral health. Br Dent J 1988; 164: 258-260.

5. Grossi S G, Zambon J J, Ho A W, Genco R J, Machtei E E, Koch G, Dunford R Hausmann E. Assessment of risk of periodontal disease I. Risk indicators for attachment loss. J Periodontal 1994; 65: 260-267.

6. Kinane D F, Chestnut I G. Smoking and periodontal disease. Critical review of ora biology and medicine 2000; 11:356-365.

7. Palmer R M Scott $D$ A, Meekin T N Wilson R F Poston R N Odell E W. Potential mechanisms of susceptibility to periodontitis in tobacco smokers. J Periodont Res 2000; 34: 363-369.
8. Palmer R M, Soory M. Chapter 6: Modifying factors: diabetes, puberty, pregnancy and the menopause and tobacco smoking. In Lindhe J, Karring T, Lang N P (eds). Clinical periodontology and implant dentistry ( $4^{\text {th }}$ ed) Oxford: Blackwell Munksgaard.

9. Schei O, Wæerhaug J, Løvdal A. Alveolar bone loss as a function of tobacco consumption. Acta Odont Scand 1959; 17:3-10

10. Feldman R S, Bravacos J S, Rose C L. Associations between smoking, different tobacco products, and periodontal disease indexes. J Periodonto/ 1983; 54: 481-487.

11. Ismail A I, Bert B A, Ekland S A. Epidemiologic patterns of smoking and periodontal disease in the United states. J Am Dent Assoc 1983; 106: 617-621.

12. Bergström J, Eliasson S. Noxious effects of cigarette smoking on periodontal health. $J$ Periodontal Res 1987; 22: 513-517.

13. Haber J, Kent R L. Cigarette smoking in a periodontal practice. J Periodonto/ 1992;63: 100-106.

14. Bergström J, Eliasson S, Dock J. Exposure to tobacco smoking and periodontal health. J Clin Periodontol 2000; 27: 61-68.

15. Bergström J, Eliasson S, Dock J. A 10 year prospective study of tobacco smoking and periodontal health. J Periodontol 2000; 71: 1338-1347.

16. Haffajee A D, Socransky S S. Relationship of cigarette smoking to attachment leve profiles. J Clin Periodonto/2001; 28: 283-295.

17. Bassiouny M A, Grant A A. The accuracy of the Schei ruler: a laboratory investigation. J Periodontol 1975; 46: 748-752.

18. Krall E A, Garvey A J, Garcia R I. Alveolar bone loss and tooth loss in male cigar and pipe smokers. JAm Dent Assoc 1999; 130: 57-64.

19. Björn $H$, Holmberg K. Radiographic determination of periodontal destruction in epidemiological research. Odontol Revy 1966; 17: 232-250.

20. Bergström J, Eliasson S. Cigarette smoking and alveolar bone height in subjects with a high standard of oral hygiene. J Clin Periodonto/ 1987: 14: 466-469.

21. Grossi S G, Genco R J, Machtei E E, Ho A W, Koch G, Dunford R G, Zambon J J, Hausmann E. Assessment of risk for periodontal disease II. Indicators for alveolar bone loss. J Periodonto/ 1995; 66: 23-29.

22. Bergström, J, Eliasson S, Preber H. Cigarette smoking and periodontal bone loss. $J$ Periodontol 1991; 62: 242-246.

23. Scott D A, Palmer R M, Stapleton J A. Validation of smoking status in clinical research into inflammatory periodontal disease: a review. J Clin Periodonto/2001:28: 715-722.

24. Bergström J, Floderus-Myred B. Co-twin control study of the relationship between smoking and some periodontal disease factors. Commun Dent Oral Epidemiol 1983 11: 113-6.

25. Preber $\mathrm{H}$, Bergström J. Occurrence of gingival bleeding in smoker and non-smoker patients. Acta Odont Scand 1985;43: 315-320.

26. Biddle $A$, Palmer R M, Wilson R F, Watts T L P. Comparison of periodontal probing measurements in smokers and non-smokers. J Clin Periodontol 2001; 28: 806-812. 